\title{
A field study on the behavior of static drill rooted nodular piles with caps under compression*
}

\author{
Jia-jin ZHOU ${ }^{1}$, Xiao-nan GONG ${ }^{\dagger 1}$, Kui-hua WANG ${ }^{1}$, Ri-hong ZHANG ${ }^{2}$ \\ ( ${ }^{1}$ Research Center of Coastal and Urban Geotechnical Engineering, Zhejiang University, Hangzhou 310058, China) \\ $\left({ }^{2}\right.$ Research and Development Department, ZCONE High-tech Pile Industry Holdings Co., Ltd., Ningbo 315000, China) \\ †E-mail: xngong@hzcnc.com
}

Received June 8, 2015; Revision accepted July 28, 2015; Crosschecked Nov. 25, 2015

\begin{abstract}
The static drill rooted nodular (SDRN) pile is a new type of composite pile that consists of a precast pile and surrounding cemented soil. Its cost advantages and environmentally friendly construction have been proven in applications in Southeast China. Moreover, the composition of pipe pile and nodular pile is based on the load transfer mechanisms of a pile foundation, which is effective in optimal design. This paper presents a field study on the behavior of SDRN piles under compression. The load-displacement response, axial force, mobilized load of pile cap, skin friction, and tip resistance of the composite pile are discussed. Here, the bilinear base load-displacement model was adopted to analyze the test results. It is found that providing caps on the static drill rooted piles takes full advantage of the static drill rooted method, and drilling and grouting into the soil beneath the cap, which can be considered a type of ground improvement treatment, can increase the bearing capacity of the pile cap; thus, setting a pile cap for this type of piles is recommended. The existence of the caps in the field tests decreased the skin friction of the upper part of pile shaft because of the additional settlement of the surrounding soil, which developed owing to the pressure from the caps. The frictional capacity of the concrete-cemented soil interface was much higher than that of the cemented soil-soil interface. The skin friction of the lower part of the pile shaft was about 1.25 times in clayey soil and 2.0 times in sandy soil compared with the bored pile. It can be concluded that the cemented soil-soil interface of the SDRN pile was probably better than the concrete-soil interface of the bored pile. The test results fitted the first stage curve of the bilinear model well, and it can be supposed that the base soil was strengthened because of the permeation of the cement paste.
\end{abstract}

Key words: Static drill rooted method, Nodular pile, Pile cap, Cemented soil, Skin friction, Mobilized base load doi: $10.1631 /$ jzus.A1500168

Document code: $A$

CLC number: TU473.1

\section{Introduction}

The static drill rooted nodular (SDRN) pile is a new type of composite pile, which uses a specific auger for stirring and grouting to form a column of cemented soil, after which the precast nodular pile is pushed into the cemented soil to form a complete pile. The detailed construction process of this composite pile was introduced in Zhou et al. (2013). The con-

\footnotetext{
${ }^{\ddagger}$ Corresponding author

* Project supported by the National Natural Science Foundation of China (Nos. 51578498 and 51579217)

(iD) ORCID: Jia-jin ZHOU, http://orcid.org/0000-0003-4267-1454; Xiao-nan GONG, http://orcid.org/0000-0001-5218-5324

(c) Zhejiang University and Springer-Verlag Berlin Heidelberg 2015
}

struction process can be concluded as follows:

1. Drilling: drilling the pile hole using a special auger;

2. Expanding: extending the drilling diameter at the bottom of the hole to form the enlarged pile base;

3. Grouting at pile base: grouting at the pile base with the cement paste formed by water and cement with a mass ratio of 0.6 , with the drill machine being lifted up and down repeatedly to make the cemented soil uniform;

4. Grouting at pile shaft and pulling out the drill machine: grouting along the hole with the cement paste with a water-cement ratio of 1.0 and stirring repeatedly to make the cemented soil uniform before pulling out the drill machine; 
5. Putting the precast pile: putting the precast nodular pile (pipe pile) into the pile hole filled with cemented soil by the action of its own gravity.

The static drill rooted method can not only avoid the compaction effect occurring in the driving process of the precast piles but also avert the mud skin effect and pile base sediment problems arising in the bored piles. In primary applications in Southeast China, the cost advantages of using the SDRN piles compared with the conventional bored piles were evident. Specifically, the statistics of a power station project showed that the cost of using the bored piles was 84.6 million CNY, while the cost of the SDRN piles to fulfill the same set of design requirements was 75.7 million CNY. Moreover, about $189688 \mathrm{~m}^{3}$ of mud was produced during the bored pile construction process, while the SDRN pile discharges about $67694 \mathrm{~m}^{3}$ of soil. Therefore, it is estimated that a $10 \%$ cost savings could be achieved by using the SDRN pile compared with the bored piles. In addition, soil emission from the nodular pile was only about $35.7 \%$ of the mud emissions from the bored piles. Because mud pollution has become a big environmental issue in China, the use of SDRN pile can help mitigate this problem. Considering these facts, this new type of composite pile is highly recommended because of its cost advantages and environmentally friendly factor.

Several Japanese researchers have studied the embedded nodular pile (Yabuuchi, 1994; Horiguchi and Karkee, 1995; Karkee et al., 1998; 1999; Borda et al., 2007), and the load transfer mechanism of the SDRN pile under vertical loading was also analyzed previously (Zhou et al., 2013). However, no research has been conducted on SDRN piles with caps. A substantial amount of research on traditional piles with caps or rafts showed that the caps would truly affect the load transfer mechanism of the piles under compression (Butterfield and Banerjee, 1971; Cooke, 1986; Chow and Teh, 1991; Zhang and Small, 2000; Prakoso and Kulhawy, 2001; Lee and Chung, 2005). Consequently, a group of field tests on SDRN piles with caps were conducted. The behavior of the test piles was analyzed based on the detailed data collected from field monitoring, and the findings are presented in this paper.

\section{Test pile description}

The piles used in the field tests were precast piles. Strain gauges used for monitoring the performance of the piles were inserted in the piles during the manufacturing process in the workshop. Two different types of nodular piles were used in the field tests: $800(600) \mathrm{mm}$ (i.e., $600-\mathrm{mm}$ pile shaft diameter, which is increased to $800 \mathrm{~mm}$ at the nodes) and $650(500) \mathrm{mm}$ nodular piles; the test pile manufacturing process is shown in Fig. 1.

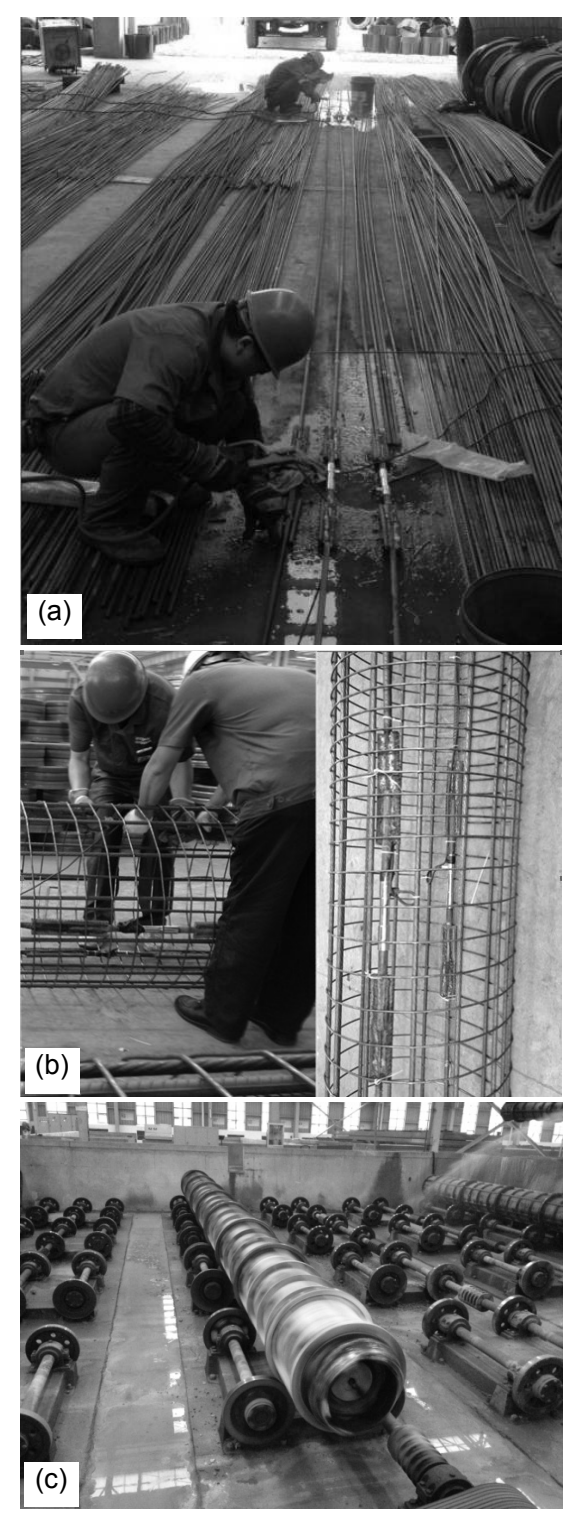

Fig. 1 Sketch of test pile manufacturing process (a) Strain gauges welding; (b) Strain gauges fixing; (c) Centrifuging process of the test pile 
According to the load transfer paths of the pile foundation, as shown in Fig. 2, where $P$ is the axial load and $L$ is the length of the pile shaft, the axial force of the upper part of the pile shaft is larger than that of the lower part, and the strength of the pile shaft at the lower part needs not to be the same as that at the pile head. It can also be seen from Fig. 2 that for frictional piles, the pile's base load is not mobilized when the applied load at the pile head is small, as shown in curve "a", and the base load is gradually mobilized as the applied pile head load increases, while it takes up a small part of the total applied load, as shown in curve "b".

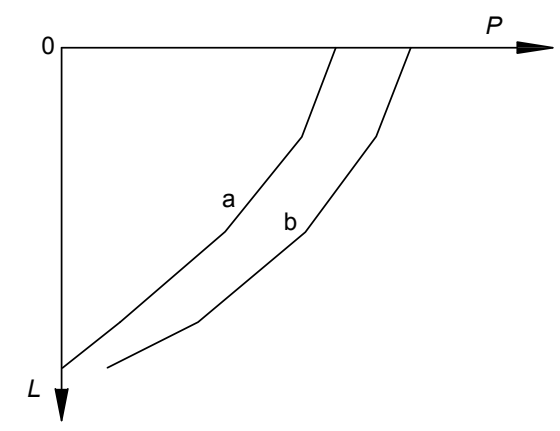

Fig. 2 Load transfer curves of frictional piles

For optimal design, a composite pile combining a pipe pile in the upper section with a matched nodular pile in the lower section was used in test piles, as shown in Fig. 3. It can be seen that the $800-\mathrm{mm}$ pipe pile is used with the $800(600) \mathrm{mm}$ nodular pile, the pipe pile and the nodular pile are both made of C80 concrete, and the wall thicknesses of the two piles are $110 \mathrm{~mm}$; therefore, the cross-sectional areas of the pipe pile and the nodular pile are $0.24 \mathrm{~m}^{2}$ and $0.17 \mathrm{~m}^{2}$, respectively. As the static drill rooted nodular pile is mostly used as frictional pile, the pile tip load is small; this pile composition form is based on the load transfer mechanisms of pile foundation. This combination is more economical compared with the traditional pile foundation, the strength of which along the pile shaft is constant. Moreover, the skin friction provided by the superficial soil layer is conversely probably smaller than that provided by the deep soil layer; the nodes along the nodular pile shaft can help guarantee the bonding strength between the precast pile and the cemented soil.

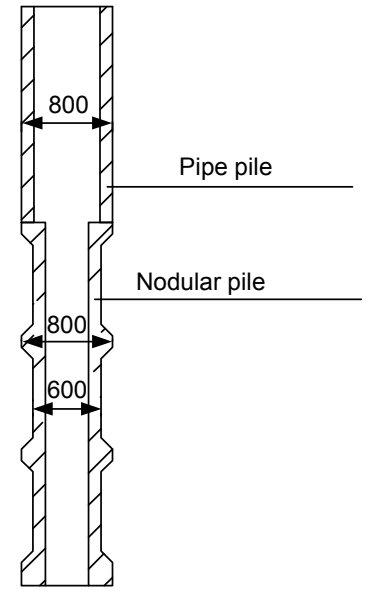

Fig. 3 Composition form of pipe pile and nodular pile (unit: $\mathbf{m m}$ )

In the field tests, two sizes of composite piles were installed for testing. One consists of a $52 \mathrm{~m}$ pipe section in the upper part, assembled from four 800 -mm pipes, each with a length of $10 \mathrm{~m}, 14 \mathrm{~m}, 14 \mathrm{~m}$, and $14 \mathrm{~m}$, in combination with a $15 \mathrm{~m}$-long $800(600) \mathrm{mm}$ nodular pile in the lower part, giving a total pile length of $67 \mathrm{~m}$. The second pile consists of a $25 \mathrm{~m}$ upper pipe section assembled from two 600-mm pipes, each with a length of $10 \mathrm{~m}$ and $15 \mathrm{~m}$, in combination with a $15 \mathrm{~m}$-long $650(500) \mathrm{mm}$ nodular pile in the lower section, thus giving a total pile length of $40 \mathrm{~m}$.

\section{Static load tests}

The field tests were conducted in Ningbo, China. A total of four $800(600) \mathrm{mm}$ and two $650(500) \mathrm{mm}$ SDRN piles (as described in Section 2) were tested. Here, two $800(600) \mathrm{mm}$ test piles and one $650(500) \mathrm{mm}$ test pile were instrumented with strain gauges. For the $800(600) \mathrm{mm}$ nodular pile, the drilling diameter was $900 \mathrm{~mm}$, and the enlarged pile base was $3 \mathrm{~m}$ high with a diameter of $1.4 \mathrm{~m}$, while the pile cap was $0.6 \mathrm{~m}$ high with a diameter of $1 \mathrm{~m}$. The strain gauges were placed according to the soil profiles at $1 \mathrm{~m}, 14 \mathrm{~m}, 55 \mathrm{~m}, 64 \mathrm{~m}$, and $66 \mathrm{~m}$ from the pile head. Every instrumented station had a set of three strain gauges.

For the $650(500) \mathrm{mm}$ nodular pile, the drilling diameter was $750 \mathrm{~mm}$, and the enlarged pile base was 
$2.4 \mathrm{~m}$ high with a diameter of $1.2 \mathrm{~m}$, while its pile cap was $0.6 \mathrm{~m}$ high with a diameter of $0.8 \mathrm{~m}$. The strain gauges were placed at $1 \mathrm{~m}, 14.5 \mathrm{~m}, 23.5 \mathrm{~m}$, and $39 \mathrm{~m}$ from the pile head, and every station was instrumented with two strain gauges. The $800(600) \mathrm{mm}$ and $650(500) \mathrm{mm}$ nodular piles are shown in Fig. 4. As the test pile was fairly long compared with its cross section, the piles in the figures are not drawn to scale, but the dimensions (in units of meters) have been shown.
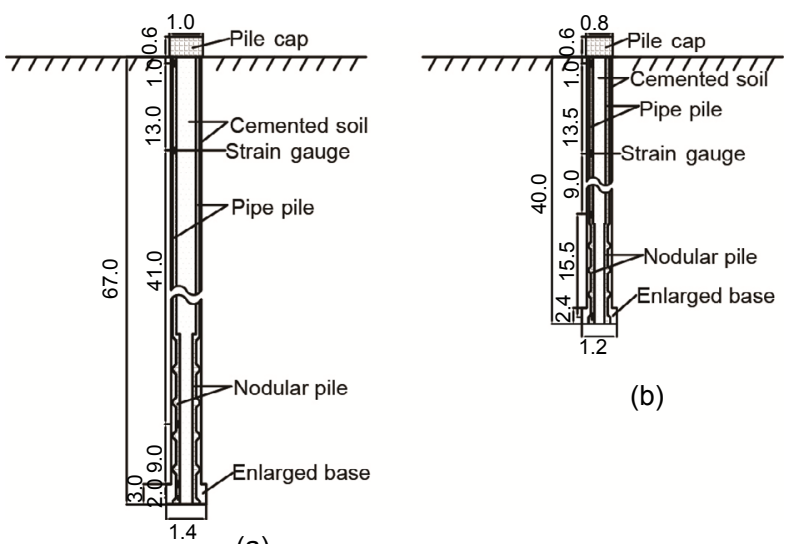

(b)

Fig. 4 Sketch of the test piles (unit: $\mathbf{m m}$ )

(a) 900-mm test pile; (b) 750-mm test pile
The scene of the test pile installation is shown in Fig. 5. It can be seen that the precast pile is put into the pile hole by the action of its own gravity. The detailed soil profiles and properties are given in Table 1 , in which $\gamma_{\text {sat }}$ is the saturated unit weight, which is gained from laboratory tests; $f_{\mathrm{ak}}$ is the bearing capacity of the soil layer; $E_{\mathrm{s}}$ is the compression modulus; $q_{\mathrm{sa}}$ and $q_{\mathrm{pa}}$ are the recommended values of ultimate skin friction and base resistance, respectively, which are estimated from the cone penetration tests (CPTs).

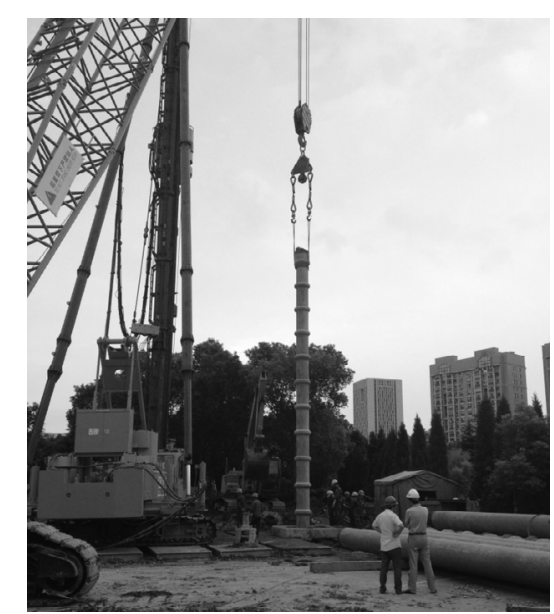

Fig. 5 Test pile installation

Table 1 Soil profiles and properties

\begin{tabular}{|c|c|c|c|c|c|c|c|c|c|c|c|c|}
\hline \multirow{2}{*}{$\begin{array}{l}\text { Soil } \\
\text { No. }\end{array}$} & \multirow{2}{*}{ Soil layer } & \multicolumn{4}{|c|}{ Thickness of soil layer $(\mathrm{m})$} & \multirow{2}{*}{$-\underset{\left(\mathrm{kN} / \mathrm{m}^{3}\right)}{\gamma_{\mathrm{sat}}}$} & \multirow{2}{*}{$\begin{array}{c}f_{\mathrm{ak}} \\
(\mathrm{kPa})\end{array}$} & \multirow{2}{*}{$\begin{array}{c}E_{\mathrm{s}} \\
(\mathrm{MPa})\end{array}$} & \multicolumn{2}{|c|}{ Pipe pile } & \multicolumn{2}{|c|}{ Bored pile } \\
\hline & & Test field & $\mathrm{TS} 3$ & TS4 & TS6 & & & & $\begin{array}{c}q_{\mathrm{sa}} \\
(\mathrm{kPa})\end{array}$ & $\begin{array}{c}q_{\mathrm{pa}} \\
(\mathrm{kPa})\end{array}$ & $\begin{array}{c}q_{\mathrm{sa}} \\
(\mathrm{kPa})\end{array}$ & $\begin{array}{c}q_{\mathrm{pa}} \\
(\mathrm{kPa})\end{array}$ \\
\hline $1-1$ & Plain fill & $4.10-0.70$ & 1.0 & 0.8 & 0.5 & 17.5 & & & & & & \\
\hline $1-2$ & Clay & $1.70-0.30$ & 0.9 & 1.7 & 0.8 & 18.4 & 80 & 4.19 & 16 & & 14 & \\
\hline 2 & Muddy clay & $13.30-0.50$ & 12.1 & 11.5 & 0.0 & 17.0 & 60 & 2.32 & 9 & & 8 & \\
\hline $5-1$ & Clay & $10.50-2.20$ & 5.4 & 4.1 & 13.1 & 18.7 & 130 & 4.27 & 22 & 750 & 20 & 320 \\
\hline $5-2$ & Silt clay & $12.00-1.90$ & 7.1 & 0.9 & 9.3 & 18.5 & 150 & 7.70 & 28 & 1200 & 26 & 450 \\
\hline $6-1$ & Silt clay & $20.00-12.30$ & 15.5 & 6.5 & 16.2 & 18.4 & 110 & 4.44 & 20 & 650 & 18 & 280 \\
\hline $6-2$ & Medium sand & $1.70-0.40$ & 1.2 & 4.0 & 2.0 & 19.8 & 200 & 25.00 & 35 & & 33 & \\
\hline $6-3$ & Clay & $13.00-5.90$ & 8.6 & 2.4 & 8.7 & 18.1 & 120 & 5.38 & 22 & 700 & 20 & 300 \\
\hline $6-4$ & Silt clay & $10.30-1.60$ & 2.6 & 4.1 & 6.1 & 18.9 & 140 & 6.74 & 29 & 800 & 27 & 350 \\
\hline $6-5$ & Gravelly sand & $5.20-0.60$ & 1.3 & 3.4 & 1.7 & 19.6 & 350 & 30.00 & 45 & 3000 & 43 & 1300 \\
\hline $7-1$ & Silt clay & $10.60-1.60$ & 5.7 & 3.2 & 4.4 & 19.0 & 180 & 8.59 & 33 & 1350 & 31 & 600 \\
\hline $7-2$ & Medium & $1.40-0.90$ & 2.8 & 5.4 & & 19.8 & 280 & 35.00 & 45 & & 43 & \\
\hline $7-3$ & Silt clay & $10.90-6.60$ & 7.3 & 2.5 & & 19.1 & 180 & 8.38 & 35 & 1400 & 33 & 650 \\
\hline $8-1$ & Medium sand & $2.40-0.70$ & 3.8 & 3.1 & & 19.8 & 300 & 35.00 & 45 & & 43 & \\
\hline $8-2$ & Silt clay & $10.00-3.60$ & 1.5 & 1.6 & & 19.3 & 210 & 7.84 & 36 & 2000 & 34 & 1100 \\
\hline $10-1$ & $\begin{array}{l}\text { Highly-weathered } \\
\text { silt sandstone }\end{array}$ & $12.10-0.50$ & 9.1 & 9.2 & & & 450 & & 55 & 4000 & 50 & 1600 \\
\hline $10-2$ & $\begin{array}{l}\text { Medium-weathered } \\
\text { silt sandstone }\end{array}$ & & 6.8 & 9.7 & & & 1100 & & 80 & 6000 & 72 & 3700 \\
\hline
\end{tabular}

TS3, TS4, and TS6 are the pile samples referring to Section 4.1 
The field tests were conducted according to the slow maintained load method, which has been described in the Chinese Technical Code for Testing of Building Foundation Piles (MOHURD, 2003). The loading system consisted of three $5000 \mathrm{kN}$ jacks, and the load was measured by an oil pressure sensor. The settlement at the pile head was derived from four dial gauges located symmetrically on the pile head. The setups used for the field tests are shown in Fig. 6.

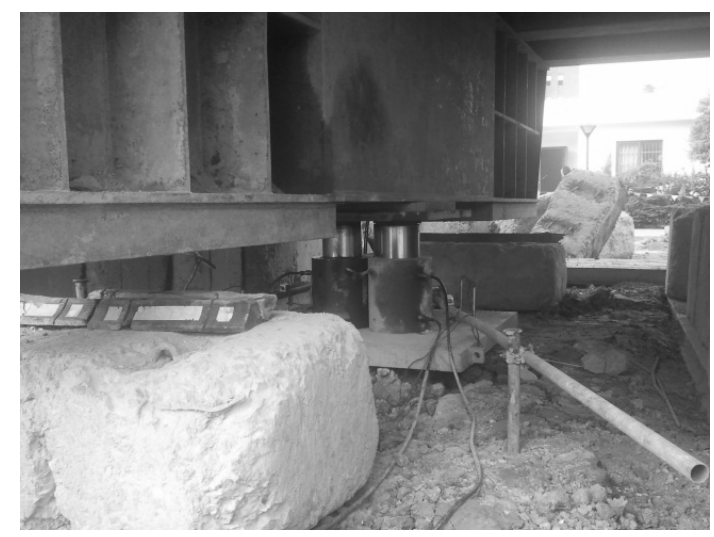

(a)

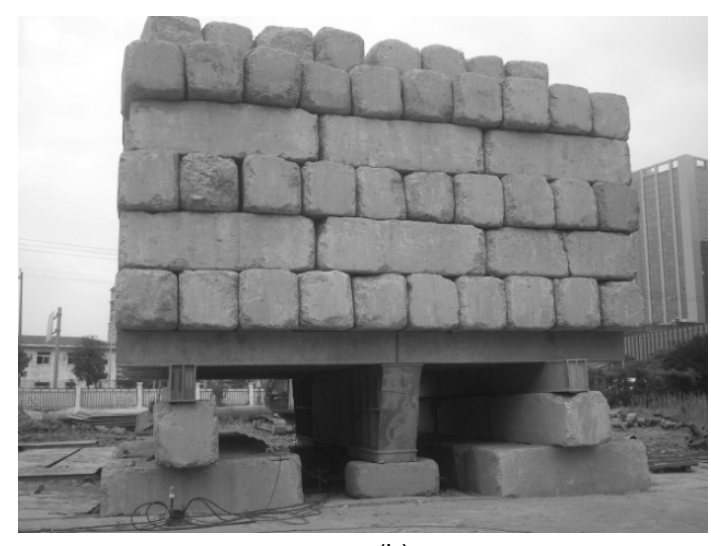

(b)

Fig. 6 Field test setups

(a) Measuring instruments; (b) Loading device

\section{Results and discussion}

\subsection{Load-displacement responses of test piles}

The load-displacement response is a useful approach to estimate the ultimate bearing capacity of a single pile. The load-displacement responses of the two types of test piles are shown in Figs. 7 and 8, respectively. Fig. 7 shows the load-displacement curves of the $900-\mathrm{mm}$ test piles (TS1-TS4) in which $800(600) \mathrm{mm}$ nodular piles were inserted. Piles TS3 and TS4 were the two piles instrumented with strain gauges. It can be seen from Fig. 7 that the settlement of each pile head increased steadily during the loading process in a slightly nonlinear fashion, with a tangential modulus that decreased (or conversely, a compressibility that increased) with load. According to the Chinese Technical Code for Testing of Building Foundation Piles (MOHURD, 2003), all the four test piles achieved the designed ultimate bearing capacities of $9100 \mathrm{kN}$. When the test piles reached the designed ultimate bearing capacity, the pile head settlements were 24.7, 36.1, 40.2, and $38.5 \mathrm{~mm}$ for the four test piles TS1-TS4, respectively. As the diameters of all the test piles were $900 \mathrm{~mm}$, the pile head settlements were $2.7 \%, 4.0 \%, 4.5 \%$, and $4.3 \%$, respectively, of the pile diameter when reaching the designed ultimate bearing capacity.

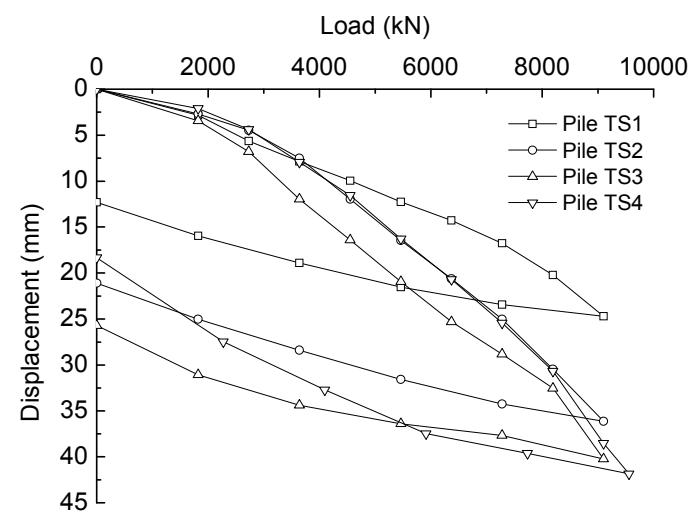

Fig. 7 Load-displacement responses of 900-mm test piles

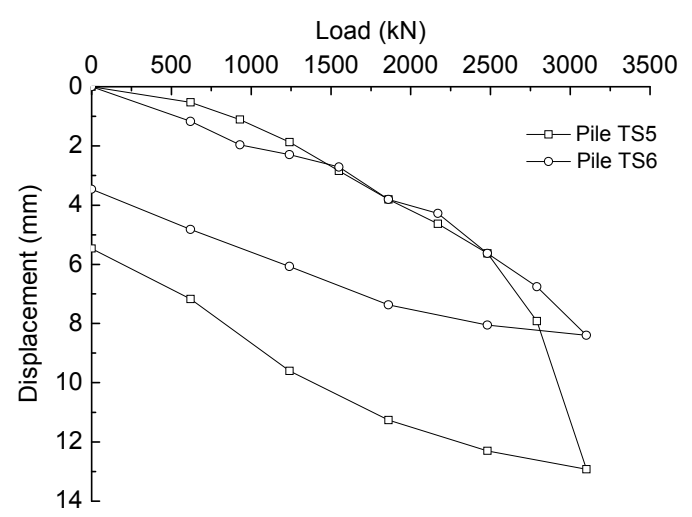

Fig. 8 Load-displacement responses of 750-mm test piles 
Fig. 8 shows the load-displacement curves of the $750 \mathrm{~mm}$ test piles (TS5 and TS6) in which $650(500) \mathrm{mm}$ nodular piles are inserted. Pile TS6 is the pile equipped with strain gauges. The test piles were loaded to the designed ultimate bearing capacity of $3100 \mathrm{kN}$. Fig. 8 shows that the settlement of pile TS6 increased steadily during the loading process, achieving the designed ultimate bearing capacity of $3100 \mathrm{kN}$. As for the pile TS5, the settlement of pile head increased sharply after the applied load reached $2170 \mathrm{kN}$, with the maximum settlement reaching $12.94 \mathrm{~mm}$ when the applied load was $3100 \mathrm{kN}$. However, it also achieved an ultimate bearing capacity of $3100 \mathrm{kN}$. The test pile head settlements were $12.9 \mathrm{~mm}$ and $8.4 \mathrm{~mm}$ when reaching the designed ultimate bearing capacity, and these are $1.7 \%$ and $1.1 \%$ of the pile diameter as the pile diameter is $750 \mathrm{~mm}$.

It can be seen from Fig. 8 that the settlements of piles TS5 and TS6 rebounded to $3.46 \mathrm{~mm}$ and $5.47 \mathrm{~mm}$, respectively, when unloaded to $0 \mathrm{kN}$. As the rebound in the pile shaft compression of the two test piles can be considered to be virtually the same when unloaded to $0 \mathrm{kN}$, the distinction between the two load-displacement curves was mainly because of different base settlements. As a result, it can be inferred that the base soil of pile TS5 is probably better than that of pile TS6.

\subsection{Axial forces of test piles}

As mentioned above, piles TS3, TS4, and TS6 are equipped with strain gauges; hence, the average axial force of the test pile can be calculated based on the measured vibration frequency of the strain gauge at the cross section.

The axial force in the test piles are shown in Figs. 9 and 10. Unfortunately, a majority of strain gauge wires in the pile TS3 were broken when the pile was inserted at a high falling speed due to the resistance of the cemented soil. As a result, the collected data from pile TS3 is insufficient to make a detailed analysis. Therefore, only the axial force curves of piles TS6 and TS4 were analyzed and presented in Figs. 9 and 10, respectively. It can be seen from Figs. 9 and 10 that the axial forces of the two test piles decrease as expected along the pile shaft because of skin friction provided by the surrounding soil, while increasing with applied axial load. Figs. 9 and
10 both show that the axial force decreases sharply at the superficial $1 \mathrm{~m}$ of pile shaft, due to load transfer to the pile cap and surrounding soil, and this phenomenon will be analyzed deeply in Section 4.3. It can also be seen from Figs. 9 and 10 that the mobilized base resistance is virtually zero or small at the initial loading stages, but it gradually develops with increasing load at the pile head.

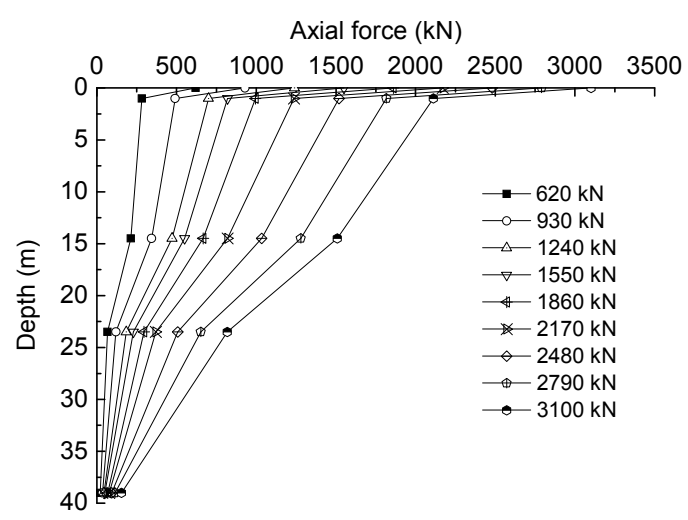

Fig. 9 Axial forces of pile TS6 under different loads

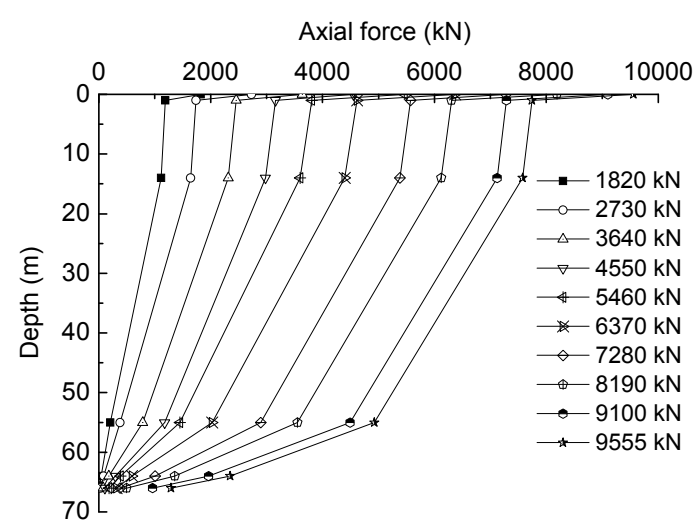

Fig. 10 Axial forces of pile TS4 under different loads

\subsection{Analysis of mobilized pile cap load}

As mentioned in Section 4.2, the pile cap and superficial 1-m pile shaft support a relatively large part of the applied load. Considering that the skin friction of the superficial $1 \mathrm{~m}$ is small, the difference of the applied pile top load and the axial force of the pile shaft that is $1 \mathrm{~m}$ from the pile top is approximately taken as the mobilized pile cap load. The mobilized pile cap loads under different loadings are shown in Figs. 11 and 12. The mobilized pile cap load seems unreasonable as the diameter of the pile cap is 
only $1 \mathrm{~m}$ and $0.8 \mathrm{~m}$ for piles TS4 and TS6, respectively, while this is because of the static drill rooted method, which improves the properties of the soil under the pile cap. According to the soil profiles in Table 1, the superficial $1-\mathrm{m}$ depth of the field is mostly plain fill comprising gravels of various grain compositions. As the specific auger for stirring and grouting can be expanded to a larger scale, the auger was expanded and the cement paste with a watercement ratio of 0.6 was injected into the superficial $1-\mathrm{m}$ soil layer during the construction process (the water-cement ratio of the cement paste was 1.0 at the pile shaft area and 0.6 at the enlarged pile base) (Zhou et al., 2013). As a result, the properties of the soil in this area were greatly improved after being injected with cement paste, and the reinforcement area was a circle with a diameter of about $4 \mathrm{~m}$ in plane (the resistance of the superficial soil layer for drilling was relatively small, and the wing of the auger could be expanded to its maximum value). The soil sample in the reinforcement area was collected for laboratory tests, and the unconfined compressive strength of the sample was about $25 \mathrm{MPa}$ after curing for $28 \mathrm{~d}$; hence, the improved soil in the reinforcement area could be considered a simplified raft. The sketch of the two test piles in the reinforcement area is shown in Fig. 13, and the pile cap and the plain concrete in the reinforcement area can be considered a whole pile cap.

Fig. 11 shows the mobilized cap load of pile TS6 It can be seen that the mobilized cap load developed with the applied load but reached an ultimate load. Specifically, the mobilized cap load of the pile TS6 increased slowly after the applied load reached $2170 \mathrm{kN}$, and the mobilized cap load reached $932 \mathrm{kN}$ when the applied load was $2170 \mathrm{kN}$, while the mobilized cap load achieved $988 \mathrm{kN}$ when the applied load reached $3100 \mathrm{kN}$. Fig. 11 also shows that the pile cap shared $54.6 \%$ of the total load when the applied load was $620 \mathrm{kN}$, reducing to $31.8 \%$ of the total load when the applied load reached $3100 \mathrm{kN}$. In consequence, the load proportion transferred to the pile cap decreases with increasing applied load at the pile head.

Fig. 12 shows the mobilized cap load of pile TS4 under different loads, and the trends of the two curves in Figs. 11 and 12 are similar, except that the mobilized cap load of pile TS4 had a small reduction after reaching the maximum value. Fig. 12 also shows that the pile cap shared $34.5 \%$ of the total load when the applied load was $1820 \mathrm{kN}$, decreasing to $19.0 \%$ of the total load when the applied load reached $9550 \mathrm{kN}$. Hence, the load proportion that was supported by the cap of the pile TS4 also decreased with increasing applied load.

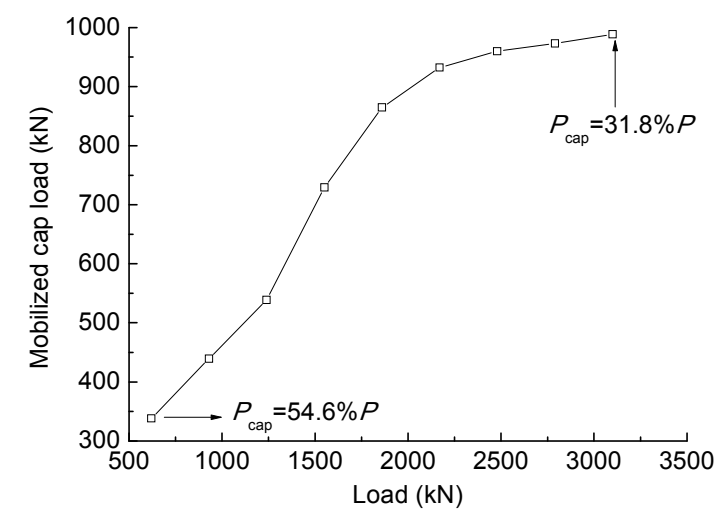

Fig. 11 Mobilized pile cap load, $\boldsymbol{P}_{\text {cap }}$, of pile TS6 under different applied loads, $P$

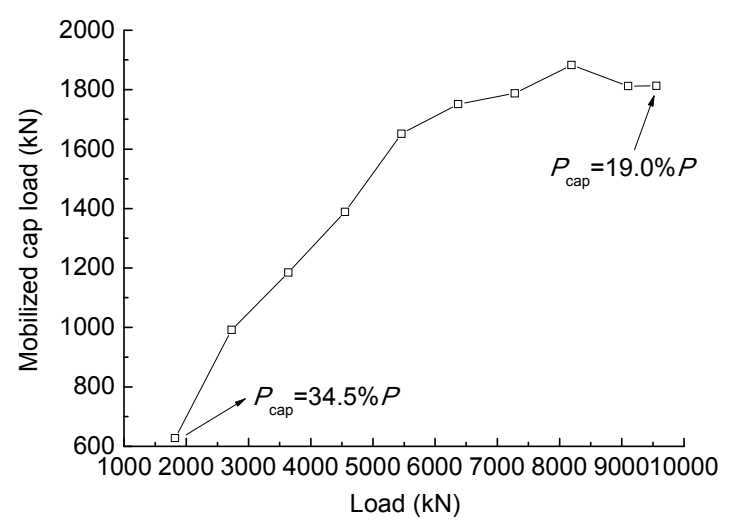

Fig. 12 Mobilized pile cap load, $P_{\text {cap }}$, of pile TS4 under different applied loads, $P$

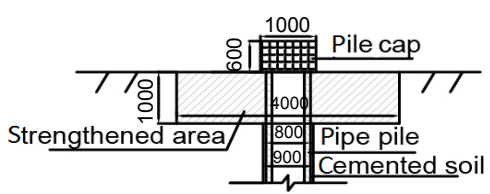

(a)

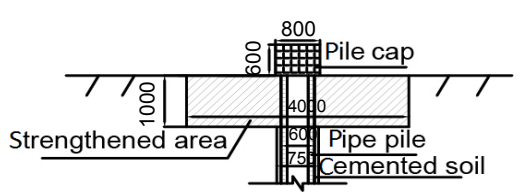

(b)

Fig. 13 Sketch of the reinforcement area of the test pile (unit: mm)

(a) Pile TS4; (b) Pile TS6 
It can be seen from Figs. 11 and 12 that the mobilized pile cap load reached $985 \mathrm{kN}$ and $1812 \mathrm{kN}$, respectively, for piles TS6 and TS4, which was relatively high for the soft soil area. Hence, the bearing capacity of the pile cap will probably be promoted by strengthening of the soil beneath with cement paste. The static drill rooted method can conveniently promote the soil properties by stirring and grouting to form cemented soil, and the reinforcement effect will probably be better when the soil is a good fill and has good permeability, such as the plain fill with gravels of different grain compositions encountered in this study.

It can also be seen in Figs. 11 and 12 that the pile cap supported $31.8 \%$ and $19.0 \%$ of the ultimate load of piles TS6 and TS4, respectively, which indicates that the load proportion that the pile cap supports probably decreases with increasing pile shaft length.

The load transfer mechanism of the test piles at the pile cap must be complex, while extensive analysis can hardly be conducted due to the lack of soil pressure sensors under the pile cap and the plain concrete raft. Hence, the pile cap and the reinforcement area under the pile cap are simply considered a whole cap herein, and it is inferred that the bearing capacity of the pile cap will probably be promoted by improving the properties of the soil beneath. Much research work is needed to provide an extensive investigation of the SDRN pile with cap.

\subsection{Analysis of skin friction along pile shaft}

As a type of composite pile foundation, precast piles and the surrounding cemented soil are considered as a whole during the load transfer process. To investigate the frictional capacity of the concretecemented soil interface, a model shearing test was conducted. Model concrete piles were made initially, as shown in Fig. 14. It can be seen that the surface of the model pile is smooth, which is similar to prototype piles. The shearing test was conducted in a model box, and the model concrete pipe was first set in the model test before the cemented soil was filled around it, as shown in Fig. 15. The ratio of the cemented soil was according to that in the field tests, and the model shearing test was conducted after curing for $28 \mathrm{~d}$, as shown in Fig. 16. Totally, three groups of shearing tests were conducted, and the maximum concrete- cemented soil interface shearing strength was about $320 \mathrm{kPa}$. More investigations on pile-soil interface of different materials will be shown in another research paper.

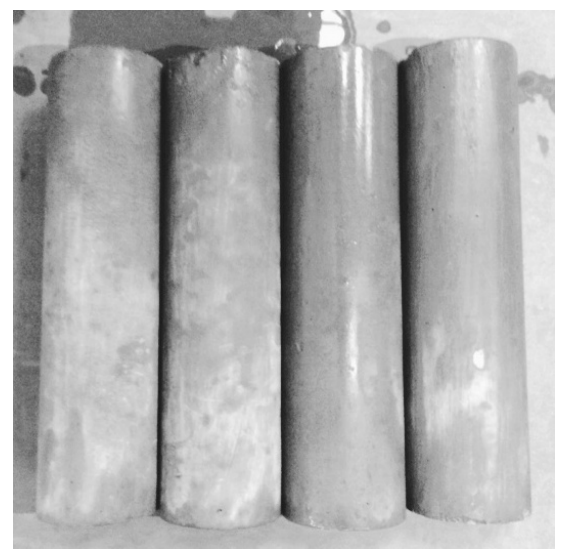

Fig. 14 Model concrete piles

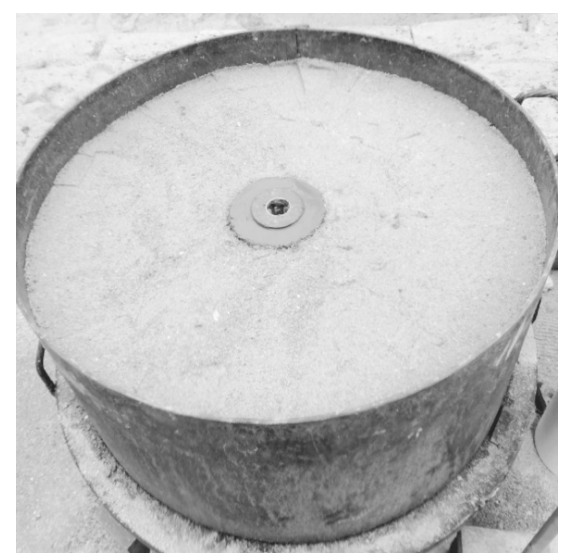

Fig. 15 Model test setups

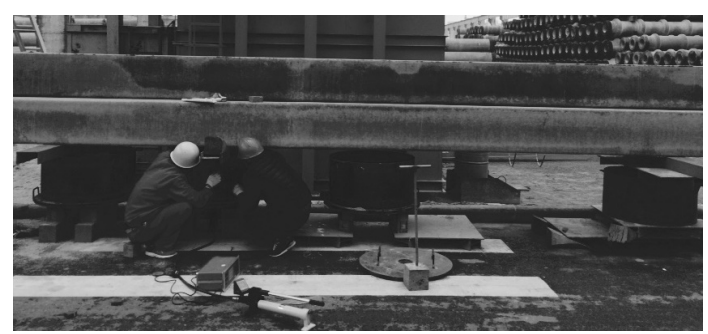

Fig. 16 Interface shearing test

It can be seen from the shearing tests that the maximum shearing strength of the concrete-cemented soil interface is much greater than that of the cemented soil-soil interface; therefore, only the relative 
displacement between the cemented soil and soil should be considered. The relative displacement between composite pile and soil can be approximately expressed as

$$
\delta_{i}=S-\sum_{j=1}^{i} \frac{L_{j}}{2}\left(\varepsilon_{j}+\varepsilon_{j+1}\right)
$$

where $S$ is the pile head settlement, $L_{j}$ is the length of pile shaft located at section $j$, and $\varepsilon_{j}$ is the strain of the reinforcing steel bar as well as the concrete located at section $j$. The pile shaft resistance $f_{\mathrm{si}}$ of the soil layer $i$ is expressed as

$$
f_{\mathrm{si}}=\frac{P_{i}-P_{i+1}}{A_{i}},
$$

where $P_{i}$ and $P_{i+1}$ are the axial forces in the pile shaft located at sections $i$ and $i+1$, respectively, and $A_{i}$ is the lateral area of the pile, namely, the lateral area of the cemented soil.

The relationships between the skin friction and the pile-soil relative displacement at different depths are shown in Figs. 17 and 18, respectively.

Fig. 17 shows the relationship between skin friction of pile TS6 and pile-soil relative displacement. It can be seen that the skin friction of each soil layer is gradually mobilized with increasing pile-soil relative displacement. The skin friction trends to be stable with the pile-soil relative displacement increasing, reaching an ultimate value, for the two shallow soil layers. In contrast, the skin friction of the deeper soil is relatively low because of the pile cap pressure on surrounding soil. The measured ultimate skin frictions of the test pile with cap with reference to clay and silt clay 1 layers are $18.9 \mathrm{kPa}$ and $32.6 \mathrm{kPa}$, respectively, while the recommended ultimate skin frictions of the bored piles given in Table 1 are $20 \mathrm{kPa}$ and $26 \mathrm{kPa}$ for the above two soil layers, that is, the measured values are, respectively, 0.95 and 1.25 times the recommended values. It has been reported that the ultimate skin friction of the SDRN pile without pile cap is $1.05-1.10$ times of the bored pile in the same soil layers (Zhou et al., 2013); hence, the existence of the pile cap seems to weaken the skin friction of the upper pile shaft while having little influence on the skin friction of the lower pile shaft.

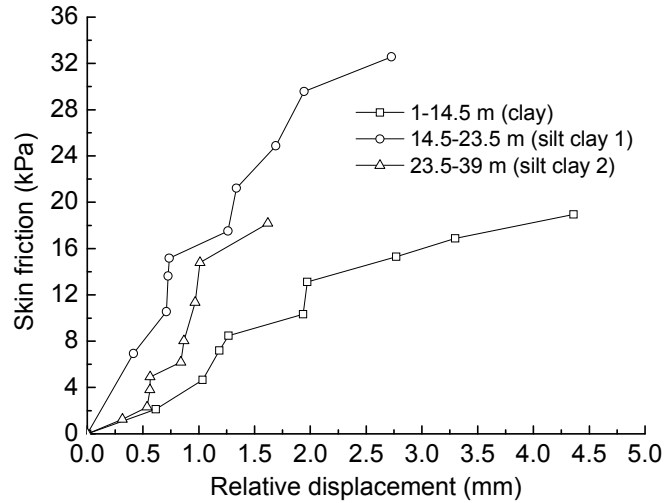

Fig. 17 Relationships between the skin friction and the pile-soil relative displacement of pile TS6 at different depths

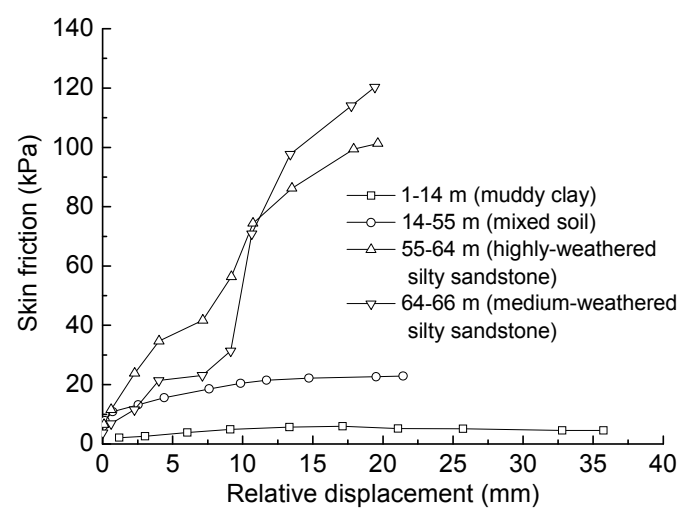

Fig. 18 Relationships between the skin friction and the pile-soil relative displacement of pile TS4 at different depths

Lee and Chung (2005) pointed out that cap-soil-pile interaction can either increase or decrease the bearing capacity of the pile: the contact pressure between cap and soil would increase the lateral normal pressure on the pile shaft and consequently increase the skin friction, while the contact pressure from the cap could also induce additional settlement in the surrounding soil and negative skin friction may occur. For the case in this study, the cap-soil interaction prevents the skin friction from being fully mobilized because of the additional settlement in the surrounding soil induced by the relatively high contact pressure from the pile cap, although the ultimate skin friction is probably promoted. Liu et al. (2010) also suggested that the cap of jet grouting soil-cement-pile strengthened pile (a similar type of composite pile foundation) makes friction resistance decrease, especially for the friction of the upper pile shaft, which agrees with the results 
in the study. The skin friction of the lower pile shaft is almost not affected as the additional settlement caused by the contact pressure is limited.

Fig. 18 shows the relationship between skin friction of pile TS4 and pile-soil relative displacement. It can be seen that the measured skin friction of the test pile with cap in respect of muddy clay is $6 \mathrm{kPa}$ which is 0.75 times the recommended value of $8 \mathrm{kPa}$ in Table 1. The measured skin friction for the mixed soil layer is $22.9 \mathrm{kPa}, 0.75$ times the mean recommended value of $30.8 \mathrm{kPa}$ from Table 1 . These results also show that the existence of pile cap decreases the skin friction of the upper pile shaft. On the other hand, the measured ultimate skin friction in respect of the highly-weathered silt sandstone is $101 \mathrm{kPa}$, which is two times the recommended value of $50 \mathrm{kPa}$. The measured maximum skin friction of mediumweathered silt sandstone, which has not been mobilized fully due to insufficient pile-soil relative displacement, is $120 \mathrm{kPa}$, which is 1.67 times the recommended value of $72 \mathrm{kPa}$.

By combining the results of piles TS6 and TS4, it can be found that the depth of influence on the skin friction of pile TS4 cap is higher than that of pile TS6 cap. This is probably because the cap of pile TS4 produces a relatively high pressure on the soil below, which leads to an enlarged affected area and results in large additional settlement of the surrounding soil. It can also be found that the measured ultimate skin friction is about two times that of the bored piles in highly-weathered silt sandstone, which reduces to 1.25 times in clay. This is probably because the permeability of highly-weathered silt sandstone is higher than that of clay, so that cement paste could more easily permeate into the former, which contributes to increasing the friction between the pile and the soil.

The number of strain gauges in the test piles is small due to the difficulty in dealing with the numerous electrical wirings of the strain gauges during the test pile manufacture, and no soil pressure sensors are equipped under the cap; hence, the measured data is perhaps not sufficient. However, some conclusions have been obtained: the existence of pile cap prevents the skin friction of the upper part of the pile shaft from being fully mobilized because of the additional settlement of the surrounding soil caused by the contact pressure from the cap, while the existence of the cemented soil promotes the skin friction between the
SDRN pile and soil. Moreover, the increased skin friction is higher in sandy soil compared with clayey soil because of the better permeability in the former. The increased friction is a function of a number of factors: the water-cement ratio of the cement paste, the property of the natural soil, the construction technology, and so forth. Much research is needed to provide an accurate assessment of the increased friction coefficient of the composite pile as well as the effect of the pile cap on the skin friction of the pile shaft.

\subsection{Analysis of mobilized pile base load}

The mobilized pile base load can be approximately estimated from the strain measured by the strain gauge that is $1 \mathrm{~m}$ from the pile base.

Fig. 19 shows the relationship between pile TS6 base load and base displacement. It can be seen that the mobilized base load increases linearly with increasing base displacement, and the base load reaches $155 \mathrm{kN}$ when the base displacement is $1.62 \mathrm{~mm}$. A bilinear base load-displacement model has been presented by Zhang and Zhang (2012):

$$
\tau_{\mathrm{b}}= \begin{cases}k_{1} S_{\mathrm{b}}, & S_{\mathrm{b}}<S_{\mathrm{bu}}, \\ k_{1} S_{\mathrm{bu}}+k_{2}\left(S_{\mathrm{b}}-S_{\mathrm{bu}}\right), & S_{\mathrm{b}} \geq S_{\mathrm{bu}},\end{cases}
$$

where $\tau_{\mathrm{b}}$ is the unit base resistance, $S_{\mathrm{b}}$ is the base settlement, $k_{1}$ and $k_{2}$ represent the compressive rigidity of the base soil in the 1st and 2nd stages of the load-displacement curve, respectively, and $S_{\text {bu }}$ is defined as the pile base settlement related to the limiting base resistance in the first stage. The first stage of the load-displacement curve of TS6 is shown in Fig. 19, and only the parameter $k_{1}$ is required to define the base load-displacement response. The value of $k_{1}$ can be estimated by the following equation suggested by Randolph and Wroth (1978):

$$
k_{1}=\frac{4 G_{\mathrm{b}}}{\pi r_{0}\left(1-v_{\mathrm{b}}\right)},
$$

where $G_{\mathrm{b}}$ and $v_{\mathrm{b}}$ are the shear modulus and Poisson's ratio of the base soil, respectively, and $r_{0}$ is the radius of the pile base. The medium sand is the base soil and Poisson's ratio $v_{\mathrm{b}}$ is 0.3 , while the shear modulus $G_{\mathrm{b}}$ can be estimated by the following equation, also proposed by Randolph and Wroth (1978): 


$$
S_{\mathrm{b}}=\frac{P_{\mathrm{b}}\left(1-v_{\mathrm{b}}\right)}{4 r_{0} G_{\mathrm{b}}},
$$

where $S_{\mathrm{b}}$ and $P_{\mathrm{b}}$ are the base settlement and mobilized base load, respectively.

The diameter of the precast nodular pile is $650 \mathrm{~mm}$, while the diameter of the enlarged cemented soil base is $1200 \mathrm{~mm}$ (as described in Section 2); therefore, the base diameter of the composite pile needs to be confirmed first. The water-cement ratio of the cement paste at the pile base is 0.6 , and the volume of the cement paste injected into the enlarged base is the same as the total volume of the enlarged base. The results of the test of a core sample previously taken from the site showed that the volume ratio of the cement paste to the soil was 2:1. Unconfined compressive strength tests conducted on the cemented soil with the above-mentioned ratio measured the unconfined compressive strength to be about $12 \mathrm{MPa}$, while the elastic modulus was estimated at $2800 \mathrm{MPa}$. Therefore, the strength of the enlarged cemented soil base is probably higher than that of medium sand at the pile base, suggesting that the enlarged cemented soil base and the precast nodular pile will act as one during the loading process; consequently, the diameter of the composite pile is considered to be $1200 \mathrm{~mm}$.

The shear modulus $G_{\mathrm{b}}$ of the pile base soil is 27.5 MPa using Eq. (5) and the curve in Fig. 19, and $k_{1}$ is estimated as $83.4 \mathrm{MPa} / \mathrm{mm}$ using Eq. (4). Hence, the relationship between the mobilized pile base load and base displacement can be expressed as

$$
\begin{aligned}
& \tau_{\mathrm{b}}=83.4 S_{\mathrm{b}}, \\
& P_{\mathrm{b}}=\pi r_{0}^{2} \tau_{\mathrm{b}}=94.3 S_{\mathrm{b}},
\end{aligned}
$$

where the units of $\tau_{\mathrm{b}}, S_{\mathrm{b}}$, and $P_{\mathrm{b}}$ are $\mathrm{MPa}, \mathrm{mm}$, and $\mathrm{MN}$, respectively.

It can be seen from Fig. 19 that the theoretical load-displacement curve compares well with the measured one. It is also found that the shear modulus of the base soil is on the high side such that the second stage of the bilinear model does not appear during the load test. A possible reason is that part of the cemented soil permeates into the base soil and strengthens the base soil as well as making it brittle.

Fig. 20 shows the relationship between pile TS4 base load and base displacement. It can be seen that the mobilized base load increases linearly with increasing base displacement before reaching a turning point when the base settlement reached $13.4 \mathrm{~mm}$, after which the mobilized base load increases more steeply with settlement. When the base settlement is $<13.4 \mathrm{~mm}$, the diameter of the enlarged cemented soil base is $1400 \mathrm{~mm}$, and the calculated shear modulus $G_{\mathrm{b} 1}$ and the compressive rigidity $k_{1}$ are $8.6 \mathrm{MPa}$ and $22.3 \mathrm{MPa} / \mathrm{mm}$, respectively. When the base settlement surpasses $13.4 \mathrm{~mm}$, whether the enlarged cemented soil base would be broken due to the steeper part of the base load-settlement curve should be taken into consideration. On the assumption that the enlarged cemented soil is not broken, the base diameter of the composite pile is $1400 \mathrm{~mm}$, and the estimated shear modulus $G_{\mathrm{b} 2}$ and the compressive rigidity $k_{2}$ are 42.8 $\mathrm{MPa}$ and $111.3 \mathrm{MPa} / \mathrm{mm}$, respectively. If the enlarged cemented soil is broken during the loading process, the diameter of the pile base reduces to

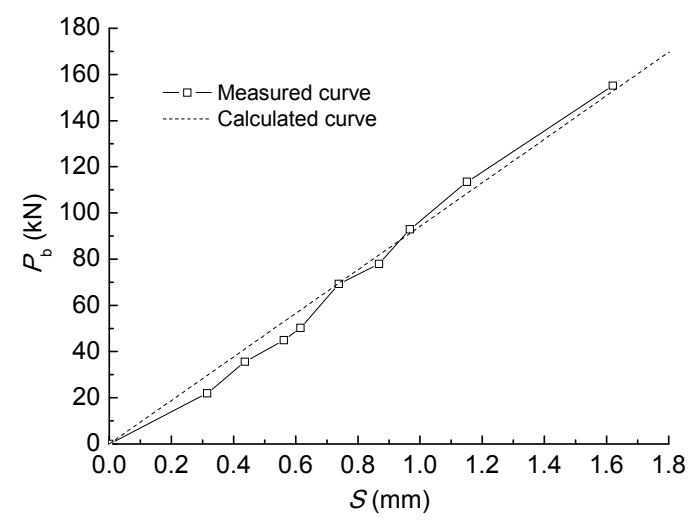

Fig. 19 Mobilized base load versus base displacement for pile TS6

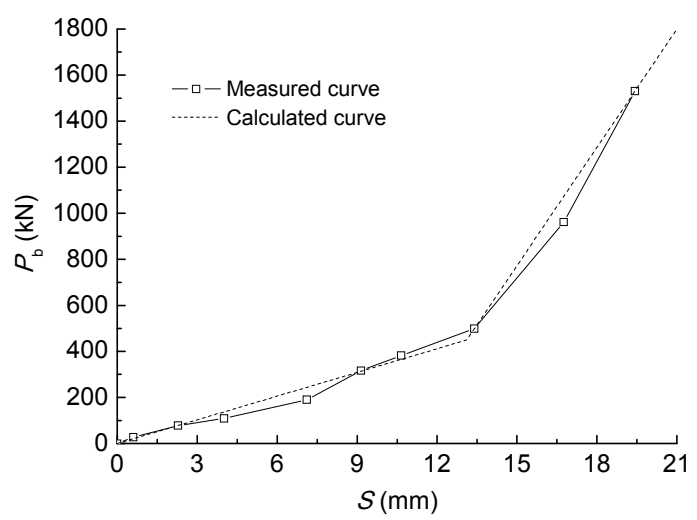

Fig. 20 Mobilized base load versus base displacement for pile TS4 
$800 \mathrm{~mm}$, and the estimated shear modulus $G_{\mathrm{b} 2}$ and the compressive rigidity $k_{2}$ are $74.9 \mathrm{MPa}$ and $340.8 \mathrm{MPa} / \mathrm{mm}$, respectively. As the unconfined compressive strength of the enlarged cemented soil base reaches $12 \mathrm{MPa}$, and its elastic modulus is $2800 \mathrm{MPa}$, it is concluded that the enlarged cemented soil base was not broken during the loading process. Therefore, the parameters for the case wherein the cemented soil is not broken are adopted, namely, the shear modulus $G_{\mathrm{b} 2}$ is $42.8 \mathrm{MPa}$ and the compressive rigidity $k_{2}$ is $111.3 \mathrm{MPa} / \mathrm{mm}$.

As a result, the base load-displacement response of pile TS4 can be expressed as

$$
\tau_{\mathrm{b}}= \begin{cases}22.3 S_{\mathrm{b}}, & S_{\mathrm{b}}<13.4 \\ 111.3\left(S_{\mathrm{b}}-13.4\right)+298.9, & S_{\mathrm{b}} \geq 13.4\end{cases}
$$

It can be seen from Fig. 20 that the theoretical load-displacement curve also compares well with the measured one. According to Table 1, the base soil of pile TS4 is medium-weathered silt sandstone, while the estimated shear modulus $G_{\mathrm{b} 1}$ is $8.6 \mathrm{MPa}$, which is a bit lower than that for medium-weathered silt sandstone. The estimated shear modulus $G_{\mathrm{b} 2}$ is 42.8 MPa, which coincides with the shear modulus of medium-weathered silt sandstone. The likely reason for the existence of the first stage of the curve is that there is a thin, soft layer between the pile base and the medium-weathered silt sandstone layer. The soft layer may have been existing originally in the mediumweathered silt sandstone layer, although inadequate stirring during the construction process may also cause the formation of a layer of uneven cemented soil with poor properties. Hence, the initial shear modulus of the base soil is lower because of the existence of a thin soft layer, and it suddenly grows larger when the pile base touches medium-weathered silt sandstone layer.

\section{Conclusions}

In this study, field tests on SDRN piles with caps were conducted to investigate their field performance. Based on the results of the field tests presented herein, the following conclusions can be drawn:

1. The cap on the pile carries part of the applied load, and the bearing capacity of the pile cap is pro- moted by grouting into the soil beneath. The cap on the short pile bears a higher proportion than that on the long pile. The static drill rooted method can conveniently strengthen the soil underneath the cap by stirring and grouting to form cemented soil, which can be considered a type of ground improvement treatment.

2. The existence of the pile cap in the field tests decreased the skin friction of the upper part of the pile shaft because of the additional settlement of the surrounding soil caused by the contact pressure from the cap. This phenomenon is obvious in this study as the cap shares a large amount of the applied load.

3. The frictional capacity of the concretecemented soil interface is much better than that of the cemented soil-soil interface, and the SDRN pile can be considered a whole in the load transfer process. The skin friction of the SDRN pile is larger than that of the bored pile in the same soil layer, and the measured skin friction of the test pile is 1.25 times and 2.0 times that of the bored pile in clay soil and sandy soil, respectively, illustrating that the increased friction is higher in the sandy soil compared with clayey soil because of the better permeability of the former.

4. The pile base load-displacement curve of the SDRN pile can be approximately represented by a bilinear model. The existence of enlarged cemented soil base increases the mobilized base load, but it should be considered whether the enlarged cemented soil base is broken during the loading process when the strength of base soil is high.

5. The cost advantages and environmentally friendly factor of the static SDRN pile has been proven in applications in Southeast China. The composition of pipe pile and nodular pile is based on the load transfer mechanisms of pile foundation, which is efficient in optimal design. The properties of clayey and sandy soils can be improved significantly by injecting cement paste, and the static drill rooted method can promote the soil properties with cement paste conveniently and efficiently. Hence, it is worth promoting this new pile construction method as well as the composite pile foundation in practice projects, especially in soft soil areas. Although some conclusions have been drawn by analyzing the results of the field tests, more study is still needed to investigate the load transfer mechanisms of this composite pile. 


\section{References}

Borda, O., Uno, M., Towhata, I., 2007. Shaft capacity of nodular piles in loose sand. Proceedings of the 49th National Conference, Japanese Geotechnical Society, Japan, 2: 1175-1176 (in Japanese).

Butterfield, R., Banerjee, P.K., 1971. The problem of pile group-pile cap interaction. Géotechnique, 21(2):135-142. [doi:10.1680/geot.1971.21.2.135]

Chow, Y.K., Teh, C.I., 1991. Pile-cap-pile-group interaction in non-homogeneous soil. Journal of Geotechnical Engineering, 117(11):1655-1668. [doi:10.1061/(ASCE)07339410(1991)117:11(1655)]

Cooke, R.W., 1986. Piled raft foundations on stiff clays-a contribution to design philosophy. Géotechnique, 36(2): 169-203. [doi:10.1680/geot.1986.36.2.169]

Horiguchi, T., Karkee, M.B., 1995. Load tests on bored PHC nodular piles in different ground conditions and the bearing capacity based on simple soil parameters. Proceedings of Technical Report of Japanese Architectural Society, 1:89-94 (in Japanese).

Karkee, M.B., Kanai, S., Horiguchi, T., 1998. Quality assurance in bored PHC nodular piles through control of design capacity based on loading test data. Proceeding of the 7th International Conference and Exhibition, Piling and Deep Foundations, Vienna, Austria, p.1-9.

Karkee, M.B., Horiguchi, T., Kishida, H., 1999. Limit state formulation for the vertical resistance of bored PHC nodular piles based on field load test results. 11th Asian Regional Conference on Soil Mechanics and Geotechnical Engineering, Kluwer Academic Publishers, Seoul, p.237-240.

Lee, S.H., Chung, C.K., 2005. An experimental study of the interaction of vertically loaded pile groups in sand. $\mathrm{Ca}$ nadian Geotechnical Journal, 42(5):1485-1493. [doi:10. 1139/t05-068]

Liu, H.L., Ren, L.W., Zheng, H., et al., 2010. Experimental research on load transfer behaviors of single jet grouting soil-cement-pile strengthened pile with cap. Chinese Journal of Rock Mechanics and Engineering, 31(5): 1395-1401 (in Chinese).

MOHURD (Ministry of Housing and Urban-Rural Development of the People's Republic of China), 2003. Technical Code for Testing of Building Foundation Piles, JGJ106-2003. China Architecture and Building Press, Beijing (in Chinese).

Prakoso, W., Kulhawy, F.H., 2001. Contribution to piled raft foundation design. Journal of Geotechnical and Geoenvironmental Engineering, 127(1):17-24. [doi:10.1061/ (ASCE)1090-0241(2001)127:1(17)]

Randolph, M.F., Wroth, C.P., 1978. Analysis of deformation of vertically loaded pile. Journal of the Geotechnical Engineering Division, 104(12):1465-1488.
Yabuuchi, S., 1994. Bearing mechanisms of muti-node piles. Proceedings of the International Offshore and Polar Engineering Conference, Osaka, Japan, p.504-507.

Zhang, H.H., Small, J.C., 2000. Analysis of capped pile groups subjected to horizontal and vertical loads. Computers and Geotechnics, 26(1):1-21. [doi:10.1016/S0266-352X(99) 00029-4]

Zhang, Q.Q., Zhang, Z.M., 2012. A simplified calculation approach for settlement of single pile and pile groups. Journal of Computing in Civil Engineering, 26(6): 750-758. [doi:10.1061/(ASCE)CP.1943-5487.0000167]

Zhou, J.J., Wang, K.H., Gong, X.N., et al., 2013. Bearing capacity and load transfer mechanism of a static drill rooted nodular pile in soft soil areas. Journal of Zhejiang University-SCIENCE A (Applied Physics \& Engineering), 14(10):705-719. [doi:10.1631/jzus.A1300139]

\section{中文概要}

\section{题 目: 带承台静钻根植竹节桩抗压承载性能试验研究}

目 的: 研究带承台静钻根植竹节桩的抗压承载性能, 承 台在荷载传递过程中所起作用, 带承台静钻根植 竹节桩的桩侧摩擦性能和桩端承载性能。

创新点: 通过带承台静钻根植竹节桩的现场静载试验对其 抗压承载性能进行分析。

方 法: 在预制桩制作过程中在桩身安置钢筋应力计 (图 1), 通过含有钢筋应力计的试桩的静载试验 对其抗压承载性能 (图 7 和 8 )、各级荷载作用下 的桩身轴力 (图 9 和 10 )、承台承载性能 (图 11 和 12)、桩侧摩擦性能 (图 18) 以及桩端承载性 能（图 19和 20) 进行分析与研究。

结 论: 1. 静钻根植工法通过搅拌注浆能够改善承台下部 土体性质, 在静钻根植桩中设置承台能充分发挥 静钻根植工法的优势, 在该种桩基中设置承台比 较合适; 2. 承台的存在使桩周土体产生沉降, 使 得试桩上部桩土相对位移较小, 从而使试桩上部 桩侧摩阻力减小, 试桩下部土体所提供的侧摩阻 力相比灌注桩都有所提高; 在粘性土中试桩桩侧 摩阻力值为灌注桩的 1.25 倍, 在砂性土中达到 2 倍, 说明试桩中水泥土-土体接触面摩擦性能优于 灌注桩混凝土-桩周土体接触面的摩擦性能, 且在 砂性土中提高程度更大; 试桩桩端荷载位移曲线 基本呈线性，与双折线模型相似; 由于有水泥土 的渗入, 桩端土的强度得到提高, 使桩端承载性 能也得到提高。

关键词: 静钻根植工法; 竹节桩; 承台; 桩侧摩阻力; 桩 端阻力 